\title{
Helena Serra
}

New University of Lisbon, Portugal

DOI: https://doi.org/10.18778/1733-8077.12.4.03

\section{Gamble on the Uncertain. Negotiating Medical Decision-Making}

Abstract The aim of this paper is to analyze the medical decision-making process in the admission of patients into a Liver Transplant Program in a hospital in Lisbon, Portugal. The relationships and main strategies established among the medical specializations involved in this process will be investigated. The theoretical basis was drawn from medical sociology, in particular, from the social constructivist approaches, which highlight the relation between medical power and knowledge in the construction of medical decision-making. I attempt to elucidate the processes of negotiation through which a medical decision is constructed. The research methodology included non-participant observation and semi-structured interviews with participants from the two medical specializations of interest: liver surgeons and hepatologists. The management of risk and uncertainty in relation to patients' access to liver transplantation is discussed and the strategic alliances that are formed during medical decision-making in search of consensus are investigated. The research findings show that medical practices and knowledge do not converge linearly to produce a coherent network of actions with a view to decision-making. Instead, medical decision-making is constructed through complex processes of negotiation. The different natures and levels of uncertainty and indetermination that are inherent in the social world of medicine have a fundamental influence on medical decision-making.

Keywords Medical Decision-Making Process; Risk and Uncertainty; Negotiation; Qualitative Study; Portugal

Helena Serra is an Associated Professor of Sociology at the Faculty of Social Sciences and Humanities of the New University of Lisbon. She has published on healthcare research and organizations and given several keynote presentations at international conferences. She is a member of the current ESA Executive Committee and President of the ISA RC52 “Sociology of Professional Groups."

email address: helena.serra@fcsh.unl.pt gies of the negotiators. During such negotiations, multiple power relationships shift continually and no party tends to dominate for long. These shifts in power are not simply the result of one party resisting the line taken by the party that currently is dominant, but are the inevitable consequence of the parties having a multiplicity of points of view. Although these perspectives are often contradictory, they must all be taken into account in order for a decision to be made.

The aim is to analyze the relationship and main strategies employed by different medical specializations, and to examine the particular forms of medical power exercised at different moments during the medical decision-making process in a liver transplantation program (LTP) in a hospital in Lisbon, Portugal. I focus on one of the most important moments of the LTP: the patient admission. This moment involves constant negotiation among the various medical specializations involved until the decision is made as to whether or not admit a patient into the program. By doing this, I will elucidate the processes of negotiation through which medical decisions are constructed, and will highlight the various discourses that reflect the different types of knowledge and power strategies involved.

\section{Theoretical Framework}

According to post-positivist approaches to the sociology of medicine, the production of knowledge and the nature of medical discourse have their basis in the construction of power strategies. For Foucault (1963), for example, the concept of power is linked directly to the concept of knowledge, which he uses as a sample case to analyze how modern approaches to the exercise of power result in certain outcomes. For Foucault, it is of interest to understand the relationship between medical discourse (a discourse that pertains to scientific knowledge) and the exercise of medical power. Foucault perceives power and knowledge to be related to such an extent that he often uses the expression power/knowledge to stress the closeness of the relation.

From a different perspective, Barber (1990) assigns two dimensions to power: knowledge and decision-making. According to him, the making of medical decision results from the interaction between knowledge and medical discourses. The various medical discourses are used to demarcate and structure medical practices and, at the same time, to highlight certain aspects of the body and the illness, and to draw distinctions between various types of patients and illnesses.

Given the importance of medical discourse in the medical decision-making process, it is pertinent to review the most significant models that are used to analyze medical discourse, namely, constructivist models. Atkinson's (1995) model was developed on the basis of his analysis of the discourse that medical specialists use in their daily practices. This model is particularly useful for analyzing the discourses of the various specializations involved in liver transplants and it enables the particular forms of medical power that are exercised at different stages of the decision-making process to be identified. He found that decisions are not made exclusively in the formal meetings at which cases are discussed; they are also made on a variety of other occasions when, 
through discourse and medical practices, the actors implement their strategies. The decisions that are made outside the formal setting of case meetings often have a decisive influence on the progress of the patient and the course that the illness takes. It is evident from the foregoing that medical knowledge, discourse, decision-making, and practice are connected intimately. Observation of various discourses and medical practices should enable us to gain insights into the medical decision-making process.

In a similar vein to Atkinson, Bloor (1976) studied variations in the assessment of patients. He argues that the nature of medical knowledge results in differences in medical routines and rules for making decisions that vary according to the content and degree of specialization, from specialist to specialist, according to the patient, and from setting to setting. Bloor argues that this variance might account for differences among the assessments made by specialists.

In addition to the above-mentioned interrelated variables, research also shows that other elements influence the work of health professionals, as well as their perceptions about their own and their colleagues' practices. Following Bloor's line of reasoning, in his observation of surgery work, Zetka (2003) argues that doctors manage to maintain professional control by delivering outputs that cannot be achieved within other types of work organization. Zetka explored medical intra-professional dynamics by comparing traditional techniques that are used in intra-abdominal surgery with a non-invasive form of surgical technology, the video laparoscope. Zetka (2003) demonstrates the effects that this new technology has on the professional lives of surgeons, namely, it challenges them to rethink their approaches to surgery and how they organize their work.

In contrast to the foregoing, most sociological and anthropological studies explain different perceptions of medical work in terms of gender relations. Cassell's (2000) study emphasized the masculine ethos of surgery and investigates the work of women in surgery, a medical specialization that is traditionally to be dominated by men. Cassell shows how, in "a man's world," gender affects the perceptions that peers, patients, and other health professionals have of a female surgeon, and also affects medical decision-making.

According to Atkinson (1995), the processes that are observed in the making of clinical decisions seem to contrast with those posited in the traditional analysis of decision-making. In a review of the literature on medical decision-making, Atkinson points to a number of shortcomings in the approaches used in influential articles. All of the studies reported in these articles used statistical models or computer-assisted simulations. Atkinson (1995:51) states that the "specific limitations of those approaches help one identify the distinctively sociological concerns that require elaboration." He proposes "to use those models and simulations as if they were ideal types, against which one's own observations and reflections can be set for heuristic purposes" (Atkinson 1995:51).

Following Atkinson's lead, the past 10 years have seen the publication of a number of sociological studies on surgery. Bosk's (2003) study of how surgeons recognize and punish themselves for their own mistakes and how they think about the problem of error reveals the complexity of medical decision-making. This work has become a classic and has set the standard for the study of medical error. Katz (1999) deconstructs the stereotypical image of the surgeon as a God-like hero and presents an alternative view that emphasizes the role of uncertainty in medical decision-making. Through her observation of the operating theatre and its practices, Katz (1999) shows how surgical practice (which is based on the biomedical model) is ritualized heavily. These rituals strengthen the attempts of biomedical practitioners to reinforce and maintain the discourse they create. In another study, Griffiths, Green, and Bendelow (2006) focus on women patients at midlife and distinguish different aspects of medical uncertainty. The authors describe the complex interaction of many factors at the macro and micro levels that affect medical decision-making. They suggest that, in contrast to the reality of the situation, the biomedical model is dominated by a concept of health risk that is context-free, in that it does not take into account the interaction of the many external factors.

In the context of medical decision-making, both risk and uncertainty play an important role; it is important to distinguish between them: risk can be assessed on the basis of the available information, whereas in the case of uncertainty, no assessment can be made because insufficient information is available. As a consequence, when the outcome of various courses of action cannot be estimated in terms of probabilities, and thus risk cannot be defined, medical decision can be viewed as being tak- en, for example, under conditions of "severe" uncertainty.

Building upon this basic distinction between risk and uncertainty, Beck's Risk Society thesis explores the concept of uncertainty further by appealing to the related concepts of contingency, indeterminism, and ignorance (Beck, Giddens, and Lash 1994). Contingency, or the simple fact that an event might occur or it might not, is a necessary condition for uncertainty. In this case, it is impossible to predict an outcome with any degree of certainty whatsoever; these events are indeterminate. In other cases, it is simply not known whether or not an outcome can be predicted, and if it can, whether or not it can be predicted with any degree of certainty. In these cases, it is necessary to act in a state of ignorance. Finally, some uncertainties derive from contingent social behaviors rather than the contingency of events. In these cases, it is recognized that scientific evaluations of the probability that a particular outcome will occur, given a certain course of action, are the result of a particular definition of the problem that is influenced by social choices.

Following Beck's line and referring to studies of risk with respect to the sociology of health, Zinn (2009) argues that the concept of risk should be refined and developed. Zinn holds that the notion of uncertainty seems to be more appropriate when we face situations that are full of uncertainties, insofar as that admitting the limitation of knowledge constitutes a fundamental factor in decision-making. Taken together, the views of Beck and Zinn present a clear distinction between the concepts of risk and uncertainty, and emphasize the ontological nature of 
the uncertainty that is inherent in the social world, through the notions of ignorance, indetermination, $\mathrm{ca}$ tastrophes, or accidents (Zinn 2009).

Although the Portuguese medical sociology literature on medical power and knowledge has gained visibility, there is still a lack of studies on the Portuguese context. Portuguese medical sociology focuses on specific aspects that explain what has brought about the increase in medical professionalism (Carapinheiro 1993; Serra 2008; Correia 2012), the centrality of the hospital in the architecture of the healthcare system-hospital-centric character (Carapinheiro 1993; Serra 2008), the colonization of management by the medical profession (Correia 2012), and medical control of technologies in healthcare (Serra 2008; 2010; 2013).

In the study reported here, I will examine the medical activity of actors in social contexts and attempt to find relationships between the social and technical factors that influence the decision as to whether or not admit a patient into the LTP. Such decision is affected from the outset by essential factors: in general, any social activity is interpreted by each actor who is involved and the interpretation is based on the meaning that the actor assigns to the activitythis applies equally to medical activities that take place in a social context and the technical issues involved.

When examining the activity of key medical practitioners, it is important to understand how each of the medical specializations constructs and consolidates its authority as power (Serra 2008). The particular authority and power that are exercised by practitioners of a particular medical specialization not be viewed as unchanging; their authority and power change continually as a result of ongoing negotiation through social strategies in daily interactions (Serra 2010). The issue of how authority is established should be regarded as a multifaceted process. The outcome of this process is determined by the access that each of the actors has to the available medical knowledge in a given social context and the power struggle that ensues between the actors on the basis of the knowledge that each possesses. On the basis of their professional authority, which is conferred by knowledge and the mastery of specific medical technologies, doctors are able to assign meaning to medical activity and determine the form that it takes, particularly in the key moments of medical decision-making.

\section{Methods}

Insofar as this study is an investigation into medical decision-making, it deals exclusively with medical work, and therefore doctors are the principal subjects of the observation and analysis. The study uses data collected from medical doctors working in a Liver Transplant Unit (LTU) in Lisbon, Portugal. The research strategy was based on non-participant observation in the LTU, carried out over a period of 18 months. This was followed subsequently by semi-structured in-depth interviews with 10 liver surgeons (all men) and 4 hepatologists (two men and two women) working in the LTU under observation. The experiences and observations made have been recorded in detailed field notes wrote outside the field. This type of methodology is suited to the nature of the problematic being studied because it makes it possible to follow the theoretical framework as the data are analyzed (Glaser and Strauss 1967).

The interviews constituted the main source of data. The semi-structured nature of the interviews made it possible to steer the conversation along the lines of a predesigned script. The questions asked corresponded to previously constructed themes: professional trajectory; technological expertise; work organization; scientific knowledge; and intra and inter-professional dynamics. The choice of this type of interview can be justified by the flexibility that this approach provides when engaging in an in-depth exploration of issues deemed important to the analysis of medical decision-making. The answers were open-ended, insofar as they allowed any information that was relevant to the investigation to be provided and certain pre-existing data to be confirmed, as well as the production of new data for analysis (Silverman 1985). These interviews yielded a wide range of different data, which demonstrated clearly the complexity of the different points of view held by different professionals and provided a wealth of material for analysis. To ensure the accuracy of both the data and subsequent qualitative content analysis, all interviews were recorded and transcribed, which led to an enormous quantity of data in the form of written text, while guaranteeing the anonymity of those interviewed. The interviews were recorded in Portuguese (participants' words were said in Portuguese) and translated into English.

From the transcribed conversations, experiences were categorized. Then, all the data that were related to these patterns were identified and related patterns were combined and catalogued into subthemes. According to Creswell (1998:25), "category formation represents the heart of qualitative data analysis." The content of the data is described in detail in the next section. Themes and dimensions are developed from the analysis of the data and presented in conjunction with my own views and those from the literature.

Intra-professional conversations that were part of the medical decision-making process regarding the admission of patients into the LTP formed the material for the analysis of certain strategies that were implemented during the processes of negotiation (Fox 1992; Lupton 2000). To gain as full a picture as possible, it was necessary to have access to the different settings, both formal and informal, in which medical decision-making occurred. Locations were selected that enabled observation of the work being carried out in the above-mentioned medical specializations. As a consequence, I was present systematically in the diagnosis rooms where these specializations were being practiced, at medical meetings, and in the wards, workrooms, and corridors. The purpose of this presence was to observe how the medical doctors/participants talked and thought about the cases dealt with in medical practice, and in particular, how the different medical specializations reached a decision about the admission of a patient to the LTP.

Patient Access to Liver Transplantation: Risk and Uncertainty Revisited

The decision as to whether a particular patient joins the waiting list for liver transplantation is based on 
the rigorous analysis of specific medical-scientific parameters and information concerning the patient and the underlying illness that gave rise to the patient's condition. The decision-making process as a whole comprises a series of individual decision-making moments in which the various medical specializations intervene with greater or lesser weight. At these key decision-making moments, the specializations of liver surgery and hepatology in particular assume a fundamental importance. The struggle for authority over the decision occurs between these two specializations, and I will focus the analysis at hand on this relation.

The weekly meeting among the medical specialists involved in liver transplantation is one of the most important moments in the decision-making process under analysis. Once a week, the director of the unit, four hepatologists (HP), and 10 liver surgeons (SG) meet in camera to discuss the new cases that have attended pre-transplantation consultation during the week. The cases are presented by the hepatologists, who introduce their new patients individually, as one of the hepatologists discloses:

As a rule, we have a first consultation. Then, the patients do the exams and they are seen afterwards. And their admission to the active list is discussed. [The patient's admission] is proposed by one of us and then it is discussed whether to admit them or not. The simple cases are presented and nobody objects. There are cases that are controversial tumors, or in other cases, the indication may be more tenuous, or the indication may already be overrun, it may already be a terminal case, or through age. [HP 12]
The above extract shows that the cases that do not raise any doubts are included automatically on the waiting list, allowing no opportunity for discussion.

These are cases whose characteristics fit into the medical-scientific parameters one finds in the liver transplantation protocol, and are therefore automatically eligible as candidates. [field note]

There is a set of possible situations that can be referred to as "controversial" and that trigger a confrontation between different types of knowledge, various discourses, and diverse scientific perspectives, not only among specializations, but also among the elements of the same specialization. As illustrated by the following extract, the final solutions are far from peaceable and, in fact, conceal truly perturbing situations where spirits are often aroused in attempts to impose different individual and/or joint strategies. Ultimately, the joint decision is accepted by all of the participants. In the following extract, we can see how one of the hepatologists portrays these moments of decision-making, revealing the different postures adapted by different professionals when faced with the same reality. The liver surgeons are described in terms of a common form of behavior that characterizes them and presents the surgical act as a privileged technique, a type of major solution that will almost always resolve the problem. According to the hepatologists, the imposition of the surgical technique as primary consideration is one of the most significant points of contention between these two specializations:

We see the problem and then talk it over with them. And normally the surgeons accept what we say.
It's just that there are clashes at times and the surgeons feel that surgery solves everything. When, for instance, there are cases in which it is more likely that the patient has everything to lose if we perform a transplant, you know. And we've already had serious problems as regards this. We're faced with a huge controversy in relation to tumors. For instance, they sent us a patient. She turned up with a tumor and counter-indications. “Oh...don't say anything. I'll bring her here, you'll go and see her, I'm sure you will, you've got a kind heart." I said, "It's not like that. We have to be serious, correct, that is, we can't be doing things that will make things worse." I did see the girl and looked at her face, she was twenty or so and I thought, she's going to die if the tumor is not removed, isn't she? If she dies after the transplant, well, that's life. Medically incorrect!...There she is, she's well, the tumor markers are okay, she's happy, she's seeing her son growing...But, I try to assert myself! But, listen, to get all this into your head! It's very complicated. [HP 11]

Another important feature revealed in this extract concerns the types of discourse that are employed in the process whereby the specific cases are discussed. The persuasive mechanisms used by the participants are worthy of note; they invoke a series of arguments that go beyond the merely scientific issues. In the arguments used by both parties, we can see the weight that uncertainty assumes with respect to medical decision-making. Both hepatologists and surgeons, particularly the latter, are sensitive to those rare instances when the result of the transplantation proves to be positive despite a negative prognosis, which undermines all that is reported in the medical literature.
As for the uncertainty that overshadows the discussion of the most controversial cases, Bosk (2003) argues that the application of a powerful battery of scientific and technical knowledge to an illness does not remove the uncertainty attached to the medical approach adapted. This is because science can be seen as an organized form of raising issues and systematic doubts about assumed concepts and facts, established methods, knowledge, and skills; it is an "open mode" of thought and research. Although medical-scientific advances resolve certain problems, they also help to produce and maintain two types of uncertainty. The first type stems from the lacunae, limitations, and errors that characterize medical knowledge at any given time. The second type of uncertainty results from the paradoxical fact that, notwithstanding its inadequacies, medical science is so vast and highly developed that no one individual can keep up with it entirely or master it perfectly.

Medical-scientific innovations in the area of liver transplantation give rise to new uncertainties, namely, with respect to the secondary effects of the new techniques, which are often unforeseeable. For instance,

The carcinogenic effects of immunosuppressors prove to be an argument used widely by the hepatologists against surgeons in the more polemic discussions. By weakening the capacity of the body to reject the liver, immunosuppressors also inhibit the defense mechanism against the development of cancerous cells. [field note]

There are other factors that also have a bearing on the decision-making process with respect to admission to 
the LTP. These factors include the age of the recipient, the existence of a dependent family, and whether the patient is thought to be "socially recuperable" (field note). In this sense, I find that other criteria, over and above medical criteria, are taken into consideration, even though this is done in a somewhat ill-defined manner. The rigorous decision criteria, which are focused exclusively on the patient's welfare, and not the effects on society, cannot always be applied rigidly with regard to the choice of transplantation recipients. In such situations, the question is not the choice of treatment for an individual patient, but the social choice as to whether a particular patient should receive a scarce resource that is not available to all.

From the outset, the opposing postures of hepatologists and surgeons are obvious. These two groups accumulate knowledge and specific experiences that emphasize the classic scission between the vision of the doctor and that of the surgeon. The more interventionist posture regarding surgery that, in general terms, characterizes the surgeons seems to be emphasized in the interaction between the two classes of specialists, as in the words of this hepatologist (HP 11)

Surgeons are always more interventionist. And so, as they've got a good technique and so on, they do, in fact, get good results. And so, well, they've got this attitude, it's more...There's something of this divergence. [field note]

The attitude that is displayed by the surgeons signifies a lesser aversion to risk, when compared to the attitude of the hepatologists. This would be expected because the act of surgery is characterized by constant risk and uncertainty, in a far more obvious manner than occurs in other medical special- izations, as one of the surgeons (SG 4) confirms:

Sometimes one has to risk it. In our profession, on has to take the risk. There are some cases where one has to run the risk. One has to give oneself the benefit of the doubt. [field note]

From the surgeons' interviews and observations, I find that, almost always, their attitude is to take the risk, even if this involves going against the scientific canons

Faced with a lack of accepted criteria to apply in relation to the most controversial cases, the tendency of surgeons is to go ahead with the transplantation beneath the watchful eye of the hepatologists who, in the majority of cases, assume the opposite posture. [field note]

For the surgeons, the surgical solution is the only option in a context where "medicine is no longer able to do anything else for the patient" (field note).

In contrast, the hepatologists argue the contrary, in voking scientific parameters and highlighting the counter-indications for transplantation with respect to specific cases and the shortage of organs. In regard to the latter issue, the hepatological discourse draws attention to the fact that one is "wasting organs on patients who cannot benefit from them, whereas others who have greater probabilities of success cannot avail themselves of this technique" (field note). With respect to this discourse, one of the surgeons says:

Really, there aren't enough livers to go round. If there were livers for everybody, I think that every patien would be put on a list. The argument would eventually be the financial one. We've got the notion that sometimes there are patients that join the list and we think this is going to be a hell of a job. That everything will go wrong and a fortnight later the patient is dead having suffered terribly. And we've got patients with a tumor that we transplant, God knows how, and a year later the patient dies, but he has had a great year. And if we were to ask this patient if that year was worthwhile...we saw the patient, and we saw the patient go to his grandson's christening...he thinks it was extraordinarily worthwhile. [SG 9]

The weight of uncertainty in medical practice is clearly reaffirmed here. As described by Katz (1999), the stereotypical image of the surgeon as a God-like hero is deconstructed and the role of uncertainty in medical decision-making is emphasized. In terms of decision-making with respect to admission to the LTP, this weight of uncertainty is evident in a dramatic manner: it is a question of assisting, or conversely, preventing patients' access to the last resort that might, or might not, prolong their lives. If this treatment is offered to the most controversial cases, other patients can be denied access to transplantation technology.

This anguish of uncertainty pervades the weekly meetings where the cases are discussed formally. In this regard, it is important to relate one of the many situations observed that illustrates the characteristic context of these precise moments of decision-making. In one of these weekly meetings, one of the hepatologists presented a case in which a confirmed malignant tumor had been diagnosed. At the consultation that preceded the meeting, the hepatologist seemed determined to make an exception, even though it was a case that ordinarily would have no indication for transplantation. The fact that it was a young patient contributed to the doctor's attitude, and the doctor took advantage of the presence of a group of surgeons to discuss the case during the consultation. It is worth drawing attention to the way in which the hepatologist stresses the importance of constructing a solid argument that will convince the surgeons to agree with the hepatologist's decision: "I've got to sell it well to the surgeons" (field note); a statement that was repeated several times during the consultation.

After referring to the tests that had been performed already and exchanging some impressions, the surgeons agreed with the hepatologist to proceed with the transplantation. But, the case still had to be presented to other members of the team, namely, the other hepatologists, at the meeting that took place immediately afterwards. At this meeting, the hepatologist in question put forward this case, the only controversial one of the week. His arguments were parried immediately by the remaining members of the team, who used rigorous medical terms and invoked scientific aspects that had been proven in the literature of the field. The hepatologist put forward counterarguments, acting as the patient's advocate. His discourse was not a medical, scientific discourse, but rather assumed the pattern of speech of a layman; he "appealed to the hearts" of other participants by using phrases such as "he's still very young," "he's got an athletic build," "and he seems to be in a fine general condition" (field note). In the end, the decision made was contrary to the hepatologist's proposal and the patient was not admitted to 
the program. Outside, once the meeting was over, the hepatologist added that, "he had been carried away by emotions and fortunately his colleagues had made him see reason." He also said, "That's why these decisions have to be discussed and assumed all together" (field note). One of the surgeons to whom this case was presented at the consultation referred to this situation later during an interview:

This patient was a terrible candidate. Now, as we've got nothing else to offer, the doctor is the patient's advocate, and the patient needs someone to plead on his behalf. Who knows, if we'd transplanted him, would it have done him harm? Another patient who was there in a worse state to be transplanted had a tumor, and was transplanted. Now he is in great form! Every patient is a patient; we don't know if this patient we're going to say "No" to is a patient to whom we should say "Yes." [SG 3]

With no doubt whatsoever, uncertainty undermines the discretion of doctors, but it does not eliminate it. In the face of uncertainty, doctors struggle to remain as objective as possible in the exercise of their discretion. They do this partly through conceptualization, either of the trajectories of the illness or of the types of treatment possible, in order to provide a considerable range of options. This strategy becomes apparent in the way in which the doctors conceptualize the cases that are prescribed for transplantation, as well as in the determination of the right timing to proceed with this treatment. Zussman (1992) refers to medical decision-making as a negotiation, insofar as the frontiers between technique and ethics are, at least in part, social constructions. As for the technical decisions, these are inherently probabilistic, all the more so because they are contested and their acceptance in practice (and even their logical or analytical validity) depends partly on the skills, dogmatism, and social position of those who defend them

\section{Strategic Alliances Around Consensus}

According to Zussman (1992), other uncertainties that arise from the social organization of medicine emerge in a far more direct form. One of the most important reasons for this direct emergence is the fact that uncertainty is heightened by a long and complex system of decision-making that emphasizes the individual responsibility of each doctor. The making of a decision does not necessarily mean that unanimity has been reached; however, within a social system, certainty requires consensus. The presence of an insistent dissident in a group of doctors who prevents the group reaching consensus is sufficient to establish doubt and introduce uncertainty.

Since the LTU consists of a multidisciplinary group of fellow professionals, it is not unreasonable to assume that decisions are and need to be made collectively. Even in this context, medicine as a profession lacks the means to impose a collective will in the face of dissent. Although decisions taken in medical work can include the decision "not to act," the doctor often still feels impelled to act, if only to respond to a patient who requests action in combating their illness: there are "countless desperate patients who insist on being transplanted by the transplantation team, after being refused admission to the program" (field note). These exceptions to the rule serve to illustrate the extent to which working conditions often have a much stronger influence than the accepted guidelines and scientific rules on the decision-making process.

The existence of diverging opinions in medicine means that differences in the definition of an illness and in the choice of the respective treatment made by individuals can compromise the stability and objectivity of the medical science body. The diagnosis process of the illness is common to all doctors; what separates them is the diagnosed illness that encompasses in itself different forms of approach. So, leaving aside a whole set of situations around which unanimity of diagnosis and therapy occurs, on the strength of a consensus based on scientific criteria, there remains the problem inherent in the cases that offer the opportunity for polemic discussion, in the sense that certain medical decisions are not unanimous among the various professionals involved.

Various strategic alliances among members within different specializations become constructed around concrete medical cases. In some situations, joint arguments are constructed that incorporate complementary knowledge in order to strengthen the argumentation of a group of doctors from the same specialization. Hepatologists and surgeons form two distinct medical corps, which present arguments to each other and engage in discourses that are at times inflamed. It can be concluded from the observations and interviews that:

each group is strategically built from internal alliances, trying to gain ground from the other camp, at times striving to win over to its cause members of the other group, or recruiting members of other specializations for the meeting, who help, with their specific skills, to put together the argumentation strategy. [field note]

The following extract from an interview with one of the surgeons demonstrates the use of strategy, in this case, that of strength in numbers:

The patient is seen by the hepatologists and then their case is discussed at a meeting. Now, to have more people to bring grist to the mill of surgery, one's mill, we realize that it's a good thing for the surgeon who's there on duty to always be present at the meetings. Therefore, today we were in the majority in relation to hepatology. [SG 4]

In reaching a decision on each case, the various discourses confront each other and often intermingle; there is constant conflict and movement between science and clinical experience, between reason and sentiment, between a greater and a lesser aversion to risk:

Uncertainty is always present and is a fundamental feature of the entire discussion. In fact, both sides use the question of uncertainty before a prognosis (which, from the outset, seems negative) as an open door to a possible exceptional case (which may not confirm the rule). The hepatologists, as usual, with their less interventionist posture, prefer not to gamble on the uncertain. [field note]

One of the hepatologists' arguments for not admitting the most controversial cases into the LTP is that the patients in this category have little time to live whether or not a transplant is performed, and, in some cases, the transplant can even hasten death. This results in high-conflict scenario regarding whether or not "to use a scarce resource" (field note) 
Therefore, the question about the success of the transplant is relative, in the sense that the duration of the graft, the survival of the patient, the quality of life, the length and conditions of rehabilitation, along with other factors, influence each doctor's perception of the probability of success. In this respect, at the moments of decision-making, the length of postoperative survival that is taken to indicate success varies considerably, depending on the specialization and the doctors concerned.

In general, I have heard the argument, especially from surgeons, that even if the patient lives just one more year with an improved quality of life, then transplantation is worthwhile, as demonstrated by surgeons talk during observation:

We really have to know how to always weigh things up and always have an objective mind along the lines of are we, in fact, going to bring benefits...In any case, if we see there's a huge opposition by hepatology to transplanting a certain patient...Here we have a scientific thing. So, it means there are arguments that...the [director] is normally silent, listening. Often, he gives his opinion, the hepatologists say "Yes" to him over and over again, and the surgeon says "No" and "No" again. But, afterwards, he has to say why it's so and why it's not. And normally a consensual decision is eventually taken. [field note]

During the discussions, "the LTU director proceeds to piece together consensus, trying to ensure that all the perspectives are considered, forcing a joint solution, trying not to interfere too much in favor of any of the groups, remaining as impartial as possible" (field note). Sometimes the director is obliged to inter- vene in a more direct manner, supporting one of the solutions clearly, but without overlooking the need to justify his position to all of the groups. This is how the director of the LTU considers his role as coordinator in such situations:

Interests converge: there's convergence from the start there's an objective convergence-the program. That is fundamental, all the rest are accidents. And they aren't many. Everyone has his specific vision. But, they all converge there. And that's what characterizes the program, and that's the mission of the person who has to direct it. This isn't the last word. No, it certainly isn't It's to inflect, so that a thing that is not being considered turns out to be. [field note]

As Childress (1991) mentions, despite the fact that the scientific criteria that underlie the decision-making process are laid down rigorously, individual assessment and individual medical decision-making remain significant factors. In this sense, decisions are affected by the subjectivity of some doctors. Such is the case regarding the admission to the LTP of certain patients, who from the start have no indication for transplantation on the basis of the scientific criteria. In this respect, it should be stressed that importance is placed on the idea that the doctor is able to practice the "art of medicine" on the basis of the doctor's knowledge of the individual aspects of the particular case. This idea was often referred to by the various doctors observed and interviewed during this study. In other words, the doctor makes the decision on the grounds of the effectiveness of the treatment for specific patients, even if this goes against the general guidelines present in the scientific criteria
Excluding exceptional cases, the criteria employed in the different decision-making contexts in the LTU are medical, insofar as they are based on the technical methods applied by doctors and are influenced by the likely success or failure of transplantation. Even so, although these criteria are essentially medical, they are not neutral. The debate over the weight and flexibility of the criteria used only partly takes account of the technical and scientific aspects, since other values also carry great weight, especially in controversial cases, as demonstrated by the data from the observations and interviews captured in this study.

\section{Conclusions}

In light of the findings presented here, I can state two main conclusions:

1. Medical decision-making process represents the culmination and, at the same time, the genesis of multiple powers/knowledge that are expressed in the medical practice. In the set of relations that have been established among the different medical specializations, there are opportunities and constraints that are exploited in the construction of reciprocal strategies, and the main strategies use uncertainty as a fundamental datum in systems for concrete action.

2. The particular forms of medical power that are exercised at different moments of decision-making demonstrate the way in which, through discourse and medical practices, the actors put their strategies into practice, influencing the trajectory of the patient and the illness, often in a decisive manner.
Findings also reveal:

- Medical decision-making can involve conflicts between different specialists regarding points of view, techniques, and priorities, as well as disputes regarding leadership and control in relation to the patient. These findings are similar to those described for situations related to what Katz and Capron (1975:29) call "catastrophic illnesses," which require specialist teams of professionals from different disciplines. The sharing of authority in decision-making (e.g., between surgeons and hepatologists) reduces the discretionary nature of decision-making.

- With respect to the decisions that are made regarding the treatment paths of patients, there is a series of both formal and informal decisions that are made, in which the doctors have a certain degree of freedom of choice. One of the most important factors that influence these decisions is uncertainty as to the results. This uncertainty was regarded as the main problem in medical activity by authors such as Fox (1988), who states that uncertainties result from the limitations of medical knowledge and other shortcomings in terms of the doctor's actual skills. The results of decisions based in part on uncertainty can often result in greater knowledge and understanding, and consequently the knowledge and experience gained can reduce uncertainty. Uncertainty can also impede this motivation to act because it generates anxiety about the effect of the medical procedures concerned. Due to this type of uncertainty, transplantation continues to be offered only to patients with a prognosis of terminal liver failure, when 
all other treatments are no longer effective; liver transplantation is seen as the last resort.

- Some of the moments of decision-making appear to provide opportunities to question and challenge the authority of different medical discourses by using a peculiar technical language, which enables each of the discourses to be individualized. Throughout the liver transplantation process, decision-making is rarely a simple and discreet act. On the contrary, the process is shared by the various participants of the medical and surgical teams, and an exchange of knowledge among the various specializations is evident.

- The exercise of decision-making is one of the most important moments of interaction among the various professionals in the liver transplantation process, who contribute to the discussion and eventual decisions on the basis of their different interests, points of view, knowledge, and experiences. In this case, decision-making is neither an isolated, individual process that operates in a social vacu- um nor a disinterested process, but rather one that is liable to be molded by social influences.

In conclusion, the study presented here demonstrates that there is a contrast between the findings of studies on clinical decision-making out of context and those that adapt the sociological approach. The latter emphasize the way in which social contexts influence decision-making and recognize that many factors interact in a complex manner at both the macro and micro level to affect medical decision-making. The findings presented here show that medical practices and knowledge do not converge linearly to produce a coherent network of actions with a view to decision-making. Instead, medical decision-making is constructed through complex processes of negotiation during which the various discourses reflect the different types of knowledge and different power strategies that are involved. In this context, the different natures and levels of uncertainty and indetermination that are inherent in the social world of medicine have a fundamental influence on medical decision-making and the construction of dominant strategies.

\section{References}

Atkinson, Paul. 1995. Medical Talk and Medical Work. London: Sage.

Barber, Bernard. 1990. "Control and Responsibility in the Powerful Professions." Pp. 311-327 in Neofunctionalist Sociology, edited by P. Colomy. Aldershot: Edward Elgar.

Beck, Ulrich, Anthony Giddens, and Scott Lash. 1994. Reflexive Modernization. Politics, Tradition, and Aesthetics in the Modern Social Order. Cambridge: Polity Press.
Cassell, Joan. 2000. The Woman in the Surgeon's Body. Cambridge, MA: Harvard University Press.

Childress, James. 1991. "Fairness in the Allocation and Delivery of Healthcare." Pp. 180-204 in A Time to Born and a Time to Die: The Ethics of Choice, edited by B. Kogan. Hawthorne, New York: Aldine de Gruyter.

Correia, Tiago. 2012. Medicina: o agir numa saúde em mudança. Lisbon: Mundos Sociais.

Creswell, John W. 1998. Qualitative Inquiry and Research Design: Choosing Among Five Traditions. London: Sage.

Foucault, Michel. 1963. Naissance de la Clinique. Paris: Gallimard.

Fox, Nicholas. 1992. The Social Meaning of Surgery. Milton Keynes, PA: Open University Press.

Fox, Renée. 1988. Essays in Medical Sociology: Journeys Into the Field. Oxford: Transaction Books.

Glaser, Barney and Anselm L. Strauss. 1967. The Discovery of Grounded Theory. Chicago: Aldine.

Griffiths, Frances, Eileen Green, and Gillian Bendelow. 2006. "Health Professionals, Their Medical Interventions, and Uncertainty: A Study Focusing on Women at Midlife." Social Science \& Medicine 62(5):1078-1090.

Katz, Jay and Alexander Capron. 1975. Catastrophic Diseases: Who Decides What? A Psychosocial and Legal Analysis of the
Problems Posed by Haemodialysis and Organ Transplantation. New York: Russell Sage Foundation.

Katz, Pearl. 1999. The Scalpel's Edge: The Culture of Surgeons. Needham Heights, MA: Allyn and Bacon.

Lupton, Deborah. 2000. “The Social Construction of Medicine and the Body." Pp. 50-63 in The Handbook of Social Studies in Health \& Medicine, edited by G. Albrecht, R. Fitzpatrick, and S. Scrimshaw. London: Sage.

Serra, Helena. 2008. Médicos e Poder: Transplantação Hepática e Tecnocracias. Lisbon: Fundação Económicas, Almedina.

Serra, Helena. 2010. "Medical Technocracies in Liver Transplantation: Drawing Boundaries in Medical Practices." Health 14(2):162-177.

Serra, Helena. 2013. "Learning From Surgery: How Medical Knowledge Is Constructed." Professions \& Professionalism 3(1):1-18.

Silverman, David. 1985. Qualitative Methodology and Sociology. Aldershot: Gower.

Zetka, James R., Jr. 2003. Surgeons and the Scope. Ithaca: Cornel University Press.

Zinn, Jens O. 2009. "The Sociology of Risk and Uncertainty: A Response to Judith Green's 'Is it Time for the Sociology of Health to Abandon rrisk??'” Health, Risk \& Society 11(6):509-526.

Zussman, Robert. 1992. Intensive Care: Medical Ethics and the Medical Profession. Chicago: University of Chicago Press.
Bloor, Michael. 1976. “Bishop Berkeley and the Adenotonsillectomy Enigma: An Exploration of Variation in the Social Construction of Medical Disposals." Sociology 10(43):43-61.

Bosk, Charles L. 2003. Forgive and Remember: Managing Medical Failure. Chicago: University of Chicago Press.

Carapinheiro, Graça. 1993. Saberes e Poderes no Hospital. Porto Edições Afrontamento
Serra, Helena. 2016. “Gamble on the Uncertain. Negotiating Medical Decision-Making." Qualitative Sociology Review 12(4):44-59. Retrieved Month, Year (http://www.qualitativesociologyreview.org/ENG/archive_eng.php). 